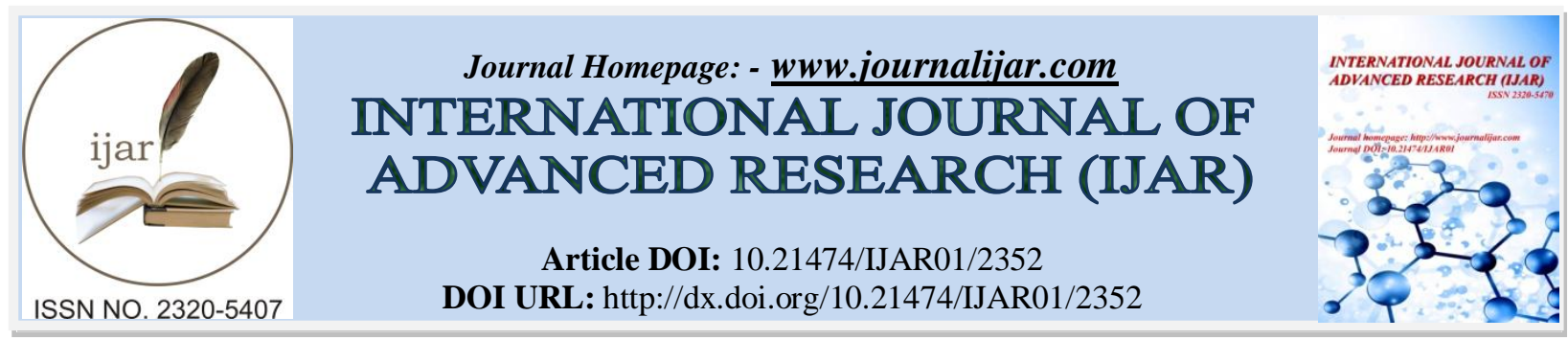

RESEARCH ARTICLE

\title{
HISTOPATHOLOGICAL STUDY OF CYSTOSCOPIC BLADDER BIOPSIES AND CYSTECTO MY SPECIMEN FROM KASHMIR.
}

\author{
Bilal Ahmed Sheikh, "Bushra Rashid Sahaf ${ }^{2}$, Rukhsana Akhter ${ }^{2}$, Farzana Manzoor ${ }^{3}$, Arshi Beig ${ }^{3}$, Saymah \\ Rashid $^{3}$ and Ruby Reshi. ${ }^{4}$. \\ 1. Associate professor, Department of Pathology, Govt Medical College, Srinagar. \\ 2. Demonstrators, Department of Pathology, Govt Medical College, Srinagar. \\ 3. Post Graduate Scholar, Department of Pathology, Govt Medical College, Srinagar. \\ 4. Professor and Head, Department of Pathology, Govt Medical College, Srinagar.
}

\section{Manuscript Info}

Manuscript History

Received: 30 September 2016

Final Accepted: 30 October 2016

Published: November 2016

\section{Abstract}

Background: Neoplastic as well as non-neoplastic lesions of urinary bladder are collectively responsible for significant mortality and morbidity. Cystoscopy with biopsy serves as a primary investigating tool for suspected lesion in bladder.

Material And Methods: All bladder biopsies and cystectomy specimens received for period of two years and three months in Department of Pathology were included in study.

Results: Among 98 cystoscopic biopsies commonest neoplasm was low grade urothelial carcinoma $(54.08 \%)$ followed by high grade urothelial carcinoma $(26.53 \%)$ and the papillary urothelial neoplasm with low malignant potential (PUNLMP) contributed to $9.18 \%$ cases while as other malignant lesions were reported in $4.08 \%$ cases. Six cases $(6.12 \%)$ were reported as inflammatory pathology.

Conclusion: Male to female ratio was noted to be $3: 1$ and the commonest neoplasm reported was low grade urothelial carcinoma.

Copy Right, IJAR, 2016,. All rights reserved.

\section{Introduction:-}

The disease of bladder are disabling than lethal ${ }^{1,2}$. Neoplastic as well as non-neoplastic lesions are collectively responsible for significant mortality and morbidity. The most common sign is gross and microscopic hematuria ${ }^{3}$. Urinary bladder cancer is sixth most common cancer worldwide and second common malignancy of genitourinary tract after prostate cancer. It contributes to $6 \%$ and $2 \%$ of cancer incidence of men and women respectively $y^{3-7}$.

Cystoscopy allows direct visualisation of bladder mucosa and therefore serves as a primary investigating tool for suspected lesion in bladder ${ }^{4}$. This study aimed to analyse the histopathological spectrum of cystoscopic biopsies and their co-relation with gender and age.

\section{Material And Methods:-}

This is a retrospective study conducted in the department of Pathology of Government Medical College and associated hospitals , Srinagar, Kashmir over a period of two years and three months (Jan 2014 to March 2016). All bladder biopsies and cystectomy specimens received during this period are included in study. Biopsies were fixed in $10 \%$ formalin for 24 hours before the tissue is processed for paraffin blocking. The representative sections were 
taken from the cystectomy specimen while grossing and processed further. Five micron sections were cut and the prepared slides were stained with Hematoxylin and Eosin $(\mathrm{H} \& \mathrm{E})$ stain. The histopathological features were studied and relevant findings were noted. Patient's history, clinical diagnosis and any significant preoperative or operative findings were also obtained from the patient's histopathological requsition forms. The World Health Organization(WHO) classification of the urinary tract tumors was used to grade the neoplastic lesions into infiltrating urothelial carcinoma, non invasive urothelial neoplasia (low grade and highgrade) and glandular neoplasm.

\section{Results:-}

This study included 98 cystectomy biopsies and 9 cystectomy specimens. The male to female ratio reported for biopsies was 3.08:1 while cystectomies were received from male patients only. Among the biopsies, commonest reported pathology was low grade urothelial carcinoma (54.08\%) followed by high grade urothelial carcinoma (26.53\%) and the papillary urothelial neoplasm with low malignant potential (PUNLMP) contributed to 9.18\% cases while as other malignant lesions were reported in $4.08 \%$ cases. Six cases $(6.12 \%)$ were reported as inflammatory pathology. Among the other neoplastic cases two were reported as adenocarcinoma, one signet ring carcinoma and one as poorly differentiated carcinoma. Table 1 shows distribution of cases with reference to male: female ratio and average age. Among 9 cystectomies, 6 cases were reported as high grade urothelial carcinoma, 2 as low grade urothelial carcinoma and 1 case on multiple sections did not show any tumor.

Table 1:- Distribution Of Cases In Relation To Gender And Age

\begin{tabular}{|l|l|l|l|l|l|l|l|l|}
\hline S. No & Lesion & $\begin{array}{l}\text { No. } \\
\text { Cases }\end{array}$ & OfPercentage & Males & Females & M:F & Mean Age Male & Mean age Female (yrs) \\
\hline 1 & Inflammatory & 6 & $6.12 \%$ & ALL & Nil & All M & 52.83 & nil \\
\hline 2 & HGUC & 26 & $26.53 \%$ & 22 & 4 & $5.5: 1$ & 64.81 & 60 \\
\hline 3 & LGUC & 53 & $54.08 \%$ & 34 & 19 & $1.78: 1$ & 55.17 & 51.78 \\
\hline 4 & PUNLMP & 9 & $9.18 \%$ & 8 & 1 & $8: 1$ & 44.5 & 55 \\
\hline 5 & Others & 4 & $4.08 \%$ & All & Nil & All M & 58 & nil \\
\hline
\end{tabular}

HGUC- High grade urothelial carcinoma, LGUC- Low grade urothelial carcinoma, PUNLMP- Papillary urothelial neoplasm of low malignant potential. Yrs-years

\section{Discussion:-}

Cystoscopy is the primary diagnostic tool in the diagnosis of urinary bladder carcinoma. Cystoscopy allows direct visualisation of bladder mucosa and therefore serves as a primary investigating tool for suspected lesion in bladder ${ }^{4}$ .The histopathological study of the cystoscopic biopsy not only gives the diagnosis but also provides the additional information to the urologist that can have impact on the treatment.

Our study included total of 98 biopsies and 9 bladder resection specimen. The male to female ratio for reported biopsies was 3.08:1 while exclusive male predominance was noted in resection specimen. Pudasainni et $\mathrm{al}^{3} \mathrm{reported}$ male to female ratio of 4.2:1 and similar results were noted by other author ${ }^{3,5-7}$. In our study the inflammatory lesions contributed to $6.12 \%$ cases. The urothelial neoplastic lesion contributed to $89.79 \%$ while other neoplastic lesions contributed to $4.08 \%$ cases. Among the urothelial neoplastic lesions, the commonest reported lesion was low grade urothelial carcinoma (54.08\%) followed by high grade $(26.53 \%)$ and then papillary urothelial neoplasm of low malignant potential $(9.18 \%)$. In a study by Kumar et $\mathrm{al}^{1}$, they reported $47 \%$ of cystoscopic biopsies to be inflammatory and about 53\% to be neoplastic. In contrast to our study they reported higher frequency of high grade urothelial carcinoma (53.57\%). In this study low grade urothelial carcinoma and Papilloma was contributing to 42.85\% and $3.57 \%$ of cases respectively. In a study by Pudasaini et al, they reported cystitis in 29\%cases and among neoplastic lesions, they found noninvasive papillary urothelial carcinoma, low grade (29\%) to be more common than infiltrative urothelial carcinoma(12.9\%). The noninvasive high grade urothelial carcinoma contributed to $6.5 \%$ of cases in this study. In the same study $3.2 \%$ cases were reported as adenocarcinoma. Similar results were noted in other studies ${ }^{6-8}$. In one more study from India, among the $50 \%$ non neoplastic cases $84 \%$ had cystitis and among the 50\% neoplastic lesion, $8 \%$ cases had infiltrative urothelial carcinoma and $4 \%$ infiltrative UC with squamous differentiation. In same study $60 \%$ had papillary urothelial carcinoma, low grade, $20 \%$ had papillary urothelial carcinoma, high grade, $4 \%$ had PUNLMP and $4 \%$ had SCC ${ }^{4}$. 
In a study from Kashmir, the commonest tumor of bladder was reported to be urothelial carcinoma while as other neoplasm contributed to $1.40 \%$ cases. In this study $27.1 \%$ had papilloma, $51.4 \%$ had low grade TCC and $21.4 \%$ had high grade $\mathrm{TCC}^{9}$.

\section{Conclusion:-}

The cystoscopy followed by biopsies helps in early diagnosis of bladder lesions. Our study included 98 cystoscopic biopsies with male to female ratio of about 3:1. The commonest bladder neoplasm was urothelial in origin with most common lesion being low grade papillary urothelial carcinoma followed by high grade ones. The papillary urothelial neoplasm of low malignant potential was noted to be lowest in frequency.

\section{Refrences:-}

1. Kumar UM, Yelikar BR. Spectrum of lesions in cystoscopic bladder biopsies- a histopathological study. Al Ameen J Med Sci 2012; 5:

2. Vinay Kumar, Abbas AK, and Fausto N. The lower urinary tract and male genital system. Robbins and Cotran. Pathologic basis of disease. 7th Edition. Philadelphia:Saunders 2004; 1026-103632- 6.

3. Pudasaini S,1 Subedi N,2 Prasad KBR,1 Rauniyar SK,1 Joshi BR,2 Bhomi K K 2. Cystoscopic bladder biopsies: A histopathological study.Nepal Med Coll J 2014; 16(1): 9-12

4. Srikousthubha, Sukesh, Raghuveer C.V, Hingle S. Profi le of Lesions in Cystoscopic Bladder Biopsies -A Histopathological Study. J Clin Diagn Res 2013; 7: 1609-12.

5. Al- Samawi AS, Aulaqi SM. Urinary bladder cancer in Yemen.Oman Med J 2013; 28: 337-40.

6. Laishram RS, Kipgen P, Laishram S, Khuraijam S, Sharma DC. Urothelial tumors of the urinary bladder in Manipur: a histopathological perspective. Asia Pacifi c Journal of Cancer Prevention. 2012; 13: 2477-9.

7. Viadya S, Lakhey M, KC S, Hirachand S. Urothelial tumors of the urinary bladder: a histopathological study of cystoscopic biopsies. J Nepal Med Assoc 2013; 52: 475-8.

8. Ahmed Z, Muzaffer S, Khan M et al. Transitional cellcarcinomas of the urinary bladder: a histopathological study.J Pak Med Assoc 2002; 52: 396-9.

9. Zubaida Rasool, Tazeen Jeelani, Farhat Mustafa and Annu Charak.Histopathological Profile of Bladder Tumors at Tertiary Care Centre in Kashmir - A Comprehensive Six Year Study .BBB[2][4][2014]280-284 